\title{
CAMINHANDO SOBRE FRONTEIRAS: O PAPEL DA EDUCAÇÃO
}

\author{
FROCHTENGARTEN, F. Caminhando sobre fronteiras: o papel da educação na vida de adultos \\ migrantes. São Paulo: Summus, 2009, 164 pgs.
}

Esta obra compõe-se de quatro capítulos, escritos propositalmente em linguagem coloquial, assim distribuído: 1) A escola: Nosso lugar de origem, 2) Viagem ao sertão, 3) Migração de retorno a Escola 4) Até Quando?

Esse livro apresenta uma sustentação teórica onde é apresentado o perfil de alunos jovens e adultos onde o autor inicia sua pesquisa metodológica. A pesquisa é baseada da experiência vivenciada do autor e da reflexão da escolarização de adultos migrantes, ocorrida no colégio Santa Cruz no curso supletivo, onde os alunos em migrantes de áreas rurais do sul da Bahia e do norte de Minas Gerais, sendo esses trabalhadores de classe popular, que abandonaram o estudo em seus lugares de origem, retomando o mesmo na idade adulta na cidade de São Paulo, o que exemplifica o cruzamento entre fronteiras: cultura rural para cultura urbana, sendo observado a questão do analfabeto para o alfabetizado, de letrados e não letrados, o conhecimento da vida social e econômica da região rural para a região urbana de práticas e conhecimentos cotidianos.

\section{Capítulo 1- A escola: Nosso lugar de origem.}

Observa-seno colégio Santa Cruz a mudança de luz, juntamente a mudança dos alunos do período vespertino para o noturno, esse formado por alunos Jovens e Adultos inscritos no curso supletivo, dentre eles funcionários que ocupam funções como varrer o chão ou vigias de portarias tomando posse da cadeira de estudante, outros com profissões de motoristas particulares e babás. $\mathrm{Na}$ pesquisa realizada foi observado o perfil dos alunos, onde os mesmos apresentavam uma faixa etária entre 20 e 30 anos, a maioria era composta por mulheres (64\%), havendo um equilíbrio entre brancos e afro descendentes. A cidade de São Paulo demonstra ser a opção mais apontada de migrantes nordestinos com baixa escolaridade, durante a pesquisa $90 \%$ dos alunos eram migrantes em sua maioria sendo nordestinos $68 \%$, baianos que totalizavam $45 \%$, entre $10 \%$ eram mineiros, $12 \%$ eram migrantes das regiões sul, Norte e Centro oeste do Brasil tendo também alguns do próprio interior paulista e fluminense. A maioria destes possui origem do campo, de regiões rurais. Com o apoio dos familiares na tentativa de mudar de vida, melhores condições de emprego e renda, justifica a iniciativa do processo migratório assim ingressando no curso supletivo na cidade de São Paulo.

Dos alunos que compunham o curso supletivo, estes também trabalhadores, apresentam marcas como graxas nos cantos das unhas, ou evidenciados pelo cheiro de cândida, o que podia ser estatisticamente notado que muitos desses estudantes possuíam cargos empregatícios em residências dentre empregadas domesticas com $45 \%$ e os que prestavam serviços e trabalhavam com comércios apresentando $19 \%$ e uma menor quantidade de $2 \%$ que possuíam funções no comércio informal. O estudo mostra que $60 \%$ desses alunos possuíam uma remuneração de 2 salários mínimos havia também os que chegavam ate 3 salários mínimos onde incluía uma maior quantidade que totalizava o numero de $80 \%$. Desses dois terço possuíam uma jornada de mais 10 horas de serviço incluindo os sábados, onde uma parcela afirmava dormir de segunda a sexta em seu local de trabalho, sendo este o único refúgio em São Paulo. Devido a rotina desses alunos o ensino noturno possui suas limitações, não sendo adequado que perdure durante as madrugadas. Dos alunos que apresentam o trabalho próximo ao colégio facilita o comparecimento, porem os alunos que possuem casas próprias ou alugadas percorrem longas distancias para seu retorno muitos chegam até as regiões periféricas. 
Atualmente sabemos que a concorrência no mercado de trabalho é grande e exigindo altos graus de conhecimentos escolares. O que no caso dos alunos do supletivo se torna inverso, pois o emprego é essencial para o estudo. A escola oferece salas espaçosas, iluminada, limpas, e imobiliário adequado, Há também aparato audiovisual para os alunos, laboratórios de ciências, sala de educação artística, biblioteca, centro de informática, quadra de esportes e campo de futebol. As aulas possuem uma interação compreendida pelos os esforços onde os alunos são analisados atraves dos seus interesses em aprofundar seus conhecimentos, nas atitudes solidárias e consideravelmente o afeto com o professor assim promovendo um clima onde o aluno retorne a escola. No supletivo os alunos são analisados pela sua frequência, onde o avanço do aluno para a seguinte etapa está interligada a sua presença nas aulas. O que permite que o professor tenha uma melhor observação da aprendizagem do aluno, assim intervindo de acordo com as necessidades de cada um. Outra forma de promover o ensino acontece fora do ambiente escolar englobando cultura e lazer na cidade São Paulo correlacionando os passeios com os conteúdos estudados, tais lugares como cinemas, teatros, exposições e parques, outros municípios também foram incluídos nesta didática.

Diante das diversas observações realizadas na pesquisa é notório as dificuldades encontradas no corpo desses estudantes, esses marcados pela longa jornada percorrida durante o dia, muitos demonstrando sono, cansaço, dores de cabeça, tremores, problemas estomacais, mau jeito nas costas pressões elevadas ou baixas, grandes fatores inclusos no processo de aprendizagem dos alunos do curso supletivo. Muitos ainda freqüentam as aulas após jornadas exaustivas de trabalho, ainda percorrendo obstáculos para permanecerem assíduos no curso, enfrentando a distancia de seus familiares, a dificuldade marcada pela distancia e as ameaças noturnas. Outro fator observado é o tratamento dos alunos para com os professores respeito transmitido em atos de condescendência muito desses tratamentos oferecidos aos professores são atribuídos de determinadas experiências dos trabalhadores como alunos que constroem as possibilidades de tais tratamentos. Cada aluno presente no curso apresentava seu esforço e dificuldades vivenciadas durante o dia a dia, e de todos os relatos podemos compreender que o jovem e adulto procura a escola com o comportamento de um ser que de forma involuntária cruza de uma hierarquia para outra tomando posse de funções rebaixadas, fato este ligado a obediência possuir fortes heranças das relações subjetivas entre ::128:: sujeitos advinda de ordens serviçais.

As práticas de ensino são compostas do letramento que está correlacionado à língua escrita e alargase a formação de pessoas envolvidas a praticas sociais, a alfabetização engloba na aquisição da aprendizagem de ler e escrever, o que condiz com letramento que interliga a utilização dessa habilidade no meio social. Tanto a alfabetização quanto o letramento possuem correlação e reciprocidade e são inseparáveis. A conexão entre as duas necessariamente não possui um seguimento linear. $O$ letramento trata-se de uma técnica contínua, que não pode ser mensurada, já o conhecimento da alfabetização está interligado ao sistema da escola, o letramento está relacionado aos convívios sociais podendo ser encontrada na família e no trabalho. O Curso supletivo possui alunos que viveram uma infância e adolescência sem freqüentar a escola, portanto sem a alfabetização e o letramento possuindo somente conhecimento da vivencia prática. O ingresso à escola desenvolve um potencial de aculturação, aproximando as praticam vivenciadas dos grupos dominantes.

Nada concretizado, o autor possuía grandes interesses intuitivosno conhecimento da vida dos migrantes do curso do supletivo, tendo um dia uma breve narração da historia de vida de alguns alunos, diante de algumas conformidades foi observado que uma determinada área rural cooperava para correlações entre a escola e a migração. Diante de uma observação que em 2007 dos 72 estudantes do supletivo eram das proximidades da região do sul do estado da Bahia e do norte de Minas, estes equivaliam a $17 \%$ dos alunos matriculados o que exigia duas salas de aula para grande quantidade de alunos. Foi formado ai um grupo sendo as Baianas de Tremedal e Belo Campo, a mineira de São João do Paraíso, estes municípios despertaram um grande interesse sendo o ponto inicial para o início da pesquisa. Esta pesquisa foi totalmente baseada no relacionamento de professor e aluno.

Com a intenção de reunir os migrantes e estudar as experiências de vida dos municípios relacionados, foi realizado uma minuciosa observação na ficha dos alunos matriculados no curso supletivo no ano de 2007, sendo analisado todos os dados que continham nas fichas nos espaços relacionado ao local de nascimento. Grupos de conversas foram selecionados sendo debatidos temas que envolvessem 
as condições de vida no local d e origem, motivos das migrações, a chegada para cidade de São Paulo, o ingresso ao trabalho, e a retomada a escola. Posteriormente entrevistas individuais foram realizadas sendo escolhidos alguns alunos de cada município para desenvolver de melhor forma suas reflexões e expressando assim de forma mais significativa. Logo após realizar a pesquisa de forma mais aprofundada possível, sendo observadas e analisadas todas as informações fornecidas pelos alunos, a pesquisa necessitava de um avanço maior.

Para maior aprofundamento da pesquisa era necessário uma visita ao local de origem alunos, assim fazendo um mergulho para conhecer as questões sociais modos e hábitos de vida, e a forma de pensar e ver a vida, as visitas foram realizadas em Tremedal, Belo Campo, e São João do Paraíso. A intenção da aproximação máxima era vivenciar e obter dados e a identidade do povo

\section{Capitulo 2- Viagem ao Sertão.}

Nessa viagem dois alunos cruzaram o cenário paulistano e posteriormente Minas Gerais. Para os alunos que vivenciavam o retorno a sua origem podia-se compreender a troca de nativos para estrangeiros, diante do reconhecimento do cenário brotava-se a familiaridade com o ambiente. A imagem da região era feita de estradas, areia e pedras que cruzavam a caatinga, nesses percursos de uma casa a outra não se avistava um ser nas longas estradas, avistava-se rebanhos macilentos, o gado tornado, o sertanejo trepado sobre o jerico, o aceno do boiadeiro, o metal e o uivo do automóvel, momentos vivenciados no sertão. As estradas compostas de casas rodeadas por cercas de tronco, sol calor empoeira, uma característica do povo era manter-se recolhidos, assim encontrava-se janelas e portas fechadas. Mesmo com a distancia entre as casas todos que ali habitavam se conheciam, território da caatinga, longas estradas que pareciam não ter fim e nem saída, diante de tal situação encontrada podia-se concluir que para o povo do sertão, o homem urbano é um frágil.

Cada região visitada correspondia a um determinado espaço que correspondia a fazenda, não era uma propriedade particular como é conhecido pelo o restante do Brasil, eram demarcações onde cada família vivia, e em alguns espaços chega-se a encontrar igrejas, escolas, e bares que tornavase ponto de encontro de muitos homens ao redor de mesas de sinuca. Foi de grande favor para a pesquisa o deslocamento do autor, ao dispor-se sair de São Paulo para conhecer as famílias irmãos e parentes do estudantes do supletivo, o que tornou mais formidável e conveniente a colheita de dados e informações. Durante as visitas eram comum o convite para uma conversa regado a cafezinho e biscoitos de goma, ou lavar as mãos em uma pia com determinada reserva de água, visitas aos redores e vizinhanças, ao plantio, açude, engenhos e escolas, o retorno para um almoço farto acompanhado de longas conversas. Nestas regiões vive-se no aguardo das águas, da seca, do plantio, da colheita, do abate, do agricultor que foi a roça ou do migrante que foi á cidade, tratava-se da cultura da população.

Os alunos do curso do supletivo possuíam pais com faixa etária dos 60 aos 80 anos, em sua maioria viviam nas mesmas fazendas desde o nascimento, esses pais se criaram aprendendo o cultivo da terra, ou trabalho no comercio. Duas décadas antes não havia energia elétrica e nem telefones, o acesso ao comércio ou aos postos médicos tinha pequenas alternativas como charretes, lombo do jumento, ou de pé, a produção agrícola gerava o mínimo de renda, as lavouras exigiam a mão de obra e colaboração de toda a família. Cabia aos pais e filhos madrugarem ate o roçado onde era cultivado e produzido feijão, milho, mandioca, cana de açúcar, mamona e algodão, enquanto isso a mãe e algumas filhas se responsabilizavam pelos deveres domésticos e os cuidados com as crianças mais novas, conseqüentemente as crianças com o tempo pegariam o ritmo de trabalho onde mais tarde seriam inseridas. Muitos dos alunos ao atingirem 9 e 10 anos eram inseridos em atividades como preparar a terra, colheitas e plantios, tratava-se de uma questão de necessidade, todos os alunos que faziam parte da pesquisa faziam parte de um contexto onde os laços familiares estava conectado com os laços de trabalho.

Com o passar do tempo às condições com que as famílias viviam em suas fazendas foram sofrendo alterações com relação a obras de infra estrutura, redes de encanamento, as regiões passaram a possuir energia elétrica, moradias de pau a pique foram modificadas por casas de alvenaria, 
mudanças climáticas também aconteceram e o que levou ao definhamento das lavouras e das grandes colheitas, devido a perda das épocas de chuva e secas, o gado sofria com a falta de chuva, e a caça do tatu passou a ser proibida faltando ate para o consumo família e a economia passava a estender-se ao sistema comercial das cidades. Diante de tais circunstancias podia-se concluir que o afastamento da escola tinha uma justificativa, os pais dos alunos do supletivo em grande parte eram analfabetos assim como seus irmãos e familiares, todos que tiveram o surgimento na roça, esses mal sabiam assinar seus nomes, poucos possuíam o conhecimento das letras, alunos do supletivo seus pais e irmãos relatavam que não freqüentavam a escola não só pelo trabalho, mais também pela dificuldade em chegar às escolas.

Os alunos do supletivo saíram de seus locais de origem meados da década de 1950, nesta época os territórios nordestinos e o norte de Minas Gerais era tomado pela seca, chegando a se estender ate a região sudeste do país. Enquanto em São Paulo havia uma grande explosão nos empreendimentos voltados para a construção civil e indústrias automobilísticas abriam portas para o mercado de trabalho, o eu se tornou um grande atrativo para o destino dos migrantes. Parte determinada pela zona oeste de São Paulo ainda apresentava-se com brejos, pastagens, e vias de terra o que possuía equivalências com as áreas rurais, pois havia também novas tendências a edificações casas, prédios, e a escola Santa Cruz. Muitos dos migrantes que chegavam a São Paulo empregavam-se em construções, empregos em mansões que estavam nas redondezas das regiões urbanas. A migração possuía correlação com o sonho de um melhor rendimento financeiro com a urbanização e a expansão da industrialização. A partir desse momento era desfeito o vinculo familiar e empregatício que existia no sertão, desfazendo a subsistência das fazendas, pois se abria portas para o acesso as regiões mais urbanizadas dando um maior potencial para migração tendo o caminho destinado a São Paulo. Tal situação pode ser compreendida que a migração não produziu o afastamento da cultura tradicional mantida no sertão, porém a mudança para a cidade marcou um novo momento onde o migrante buscava melhores condições de vida assim deixando para traz suas origens e assim a migração tornava-se uma chance secundária que conseqüentemente levaria ao abandono da cultura sertaneja. Dos alunos migrantes do supletivo muitos relatavam o desejo de conquista melhores remunerações, e poder ser alguém em sua maioria relatam que a migração

::130:: possuía a ênfase de buscar trabalho e não estudos, a migração para uma cidade grande permitiu aos alunos do sertão uma forma da desvinculação com a identidade gerada na cultura rural do sertão, e mesmo com as dificuldades encontradas na vida urbana, associada a trabalho e estudo, gerando um papel social significante na vida dos migrantes.

\section{Capítulo 3- Migração de Retorno á Escola}

Com as experiências e informações vivenciadas no dia a dia do sertão, era perceptível que os componentes da cultura material e símbolos urbanos não possui agregação com os limites das cidades. O retorno a cidade de São Paulo descruzando do meio rural para o meio urbano, o clima do supletivo era formado por generalidades do sertão, tendo maior repercussão da viagem entre os próprios alunos. A vida vivida pelos migrantes na cidade grande possuía muitas diferenças da vivida no meio rural, a rotina do camponês é formada por impressões duradouras e uniformes do mundo possuindo características regulares e tênues, já a vida urbana oferece grandes mudanças bruscas favorecendo o desencontro sobre os homens, promovendo o aumento nos estímulos nervosos em altas intensidades. Alunos relatam que a vida do homem rural sempre possui a mesma rotina com a mesma continuidade, ao contrário da vida urbana onde tudo é novo e inconstante.

De acordo comas situações que podem ser geradas pelas mudanças constantes podem pode promover ameaças as adaptações ao meio, o que faz com que homens progridam em mecanismos psíquicos sistematizados no domínio do intelecto. Processos como esses que são vividos no meio urbano onde os homens transformam em atitudes triviais e assim possuindo as diferenças entre uns e outros. Tal circunstancia está associada a economia monetária impulsionada pelos motivos pecuniários que definem a região urbana, este processo da vida metropolitana possui características onde ligam-se em feições utilitaristas. Esses percursos com grandes alterações nas atividades metropolitanas ordena uma interação das tarefas com as demais relações em um calendário impessoal. Um dos alunos durante a pesquisa relata que a vida no meio urbano passa a ser mediada pelo meio externa, pois o ser perde a direção de seu tempo. Essas grandes diferenças entre o 
campo e os tempos da cidade, o movimento urbano acelerado domina a cultura. Grandes cidades são centros de disseminação dos meios de expansão da cultura, o consumo, o ritmo industrial, a produção de bens simbólicos são sempre situações novas.

Devem-se reconhecer as condições dos alunos do supletivo e suas relações como trabalhadores, a permanência desses na cidade de São Paulo possui correlações com a compreensão da capacidade funcional pela cultura objetiva. $O$ arrasto com que as lacunas que a vida percorre integrando o processo cultural não são desperdiçadas pela vivencia na cidade, a grande finalidade que a escola assume na integração das subjetividades migrantes e sertanejas na interação com a sociedade urbana. Diante desse pensamento tem-se como compreensão entre as características da cultura escola e da cultura popular.

A viagem que permitiu um maior contato e conhecimento da vida das relações e formações sociais permitiu vivenciar também a relação do homem com a natureza, a partir do contato e das analises sobre os fenômenos naturais, os processos e recursos dos homens do sertão foram os principais temas que formaram os princípios e direções das conversas escolares com os migrantes. Todos os assuntos nortearam os diálogos e promoveram aquisições de conhecimentos sendo um estudo que serviu como instrumento para analisar as concepções da cultura escolar e cultura popular. Diante de todo os momentos vividos em diversas visitas as variadas fazendas o autor pode vivenciar o modo de vida daqueles moradores, cada problema, vivido em cada casa, o modo de trabalho de cada família, as crenças e hábitos de vida, a produção de cada família nas áreas rurais, o sustento para o consumo, sistemas de trabalho, tecnologias utilizadas, o cultivo, a integração das fazendas associadas aos comércios, enfim todos as características que formam a cultura do povo do sertão.

Podiam-se compreender as diferenças da visão do homem urbano, onde a riqueza do conhecimento é evidente, já em homens da roça é detida as condições em que vivem. Para o homem do sertão o seu labor é fruto de conhecimentos transmitidos por antecedentes familiares, o saber para esses habitantes é dirigido pela experiência um exemplo simples é a forma de associar a distancia ao tempo, onde para o homem do sertão uma légua corresponde a uma hora de caminhada. Já em uma sociedade urbanizada a forma do conhecimento é letrada correlacionando-se a métodos de pensamentos de praticas de sublimes experiências imediatas, inferindo o efeito as abstrações. São situações diferentes mais que possuem muitas vezes um convívio em comum como, por exemplo, uma situação pedagógica que ocorrera no supletivo, a atividade que os alunos trabalhavam se tratava com operações intelectuais descontextualizadas, os dois eram estudantes e estavam a muito tempo sem o convívio em uma sala de aula. A assiduidade na escola para o sertanejo não é uma questão fundamental onde seja uma forma de garantir a seu desenvolvimento através do das formas letradas de pensamento, mais a escola nesses casos traz o papel na aquisição do conhecimento em operações cognitivas descontextualizadas que muitas vezes é necessária na urbanidade.

Exercendo uma função essencial a escola se torna o local da escrita, onde se desenvolve a expressão que se associa a comunicação, a separação entre o autor e o seu produto. Nos instrumentos pedagógicos podem-se aplicar habilidades de auto instrução, função essa que pode ser utilizada nas atividades diárias de como seguir uma lista de procedimentos, a escola pode ser uma forma de criação de projetos que englobe predições, controles, planejamentos, hipóteses e troca de aprendizagem assim ocorrendo transferência de conhecimento de todos que convivem naquele meio. Enfim a escola apresenta varias maneiras de compreensões afastada dos automatismos do dia a dia. Os métodos de ensino possuem uma grande variedade, onde as competências e o potencial dos alunos são valorizados, sendo um marco inicial para a aquisição da aprendizagem.

Os conhecimentos dos alunos que são trazidos para escola pode englobar temas e assuntos já adquirido em situações posteriores durante o processo escolar ou conhecimentos alcançados durante a rotina e a passagem da vida. Alunos adultos que possuíram o convívio na escola, as aprendizagens e experiências obtidas em outros processos de ensino promovem um alargamento na predição e no esclarecimento de alguns episódios.Conhecimentos obtidos são como sistemas que simbolizam a realidade que vista pelo o individuo se torna coerente, devido a isso os saberes do cotidiano se tornam significativos e não possuem mudanças em poucas tarefas. Enfatizar a necessidade do conhecimento prévio para a aquisição do saber ao encontro de práticas pedagógicas desenvolve condições e suposições para a contextualização dos alunos. A desvinculação do aluno 
migrante da cultura do sertão com a expansão de áreas rurais e sistemas econômicos associado a inclusão deste a uma escola são requisitos dos processos de uma vida urbana, o aluno adulto ao integrar-se a ciência é conduzido pela compreensão de que está preparado para inteirar a todos os homens.

\section{Capítulo 4- Até Quando?}

O autor em sua pesquisa objetivou-se aproximar dos alunos da escola Santa Cruze da sociedade do sertão com o intuito de questionar as ingerências da vivencia estudantil desses alunos e conhecer seus pensamentos e projetos para o futuro, assim compreender as características desses estudantes e os motivos que os levaram a migração. Durante todo o processo da pesquisa, entrevistas e conversas, muitas interferências surgiram com relação aos fatores que os trouxeram ao retorno a escola, quando argumentados muitos esclareceram a vontade de mudar de vida, sabendo que essa justificativa possuíra muitos outros significados vagos para a diversidade de projetos, podendo expressar o ingresso a empregos qualificados ou a uma mudança promissora no convívio social. Independente da justificativa do reingresso desses migrantes a escola possui o intuito da promoção no nível econômico onde deu-se a iniciativa da saída do meio rural, meio em que não poderiam galgar tal pretensão. Para a escola tal iniciativa torna-se um processo que acrescenta a migração, a efetivação na sala de aula tornou-se uma ferramenta para enfatizar o deslocamento do meio rural para o meio urbano.

O processo de ensino no supletivo excede a sala de aula, o contato dos alunos a ambientes culturais e de lazer engloba temas pedagógicos permitindo o acesso ao conhecimento e o aumento do horizonte desses alunos, ampliando suas linguagens, e visão estética, métodos como este, promove a abertura aos modos, hábitos de vida e cultura popular, e historia de vida, fatores estes que muitas vezes não pode ser vivenciado no cotidiano. As mudanças, experiências e aprendizagens desenvolvidas nesses alunos vividas no letramento ampliam expectativas brecadas pelo analfabetismo traduzida como cegueira. Os métodos de escrita e leitura são praticados pelos alunos como formas de revelação, o

::132:: letramento permitia a esses alunos um distanciamento do cenário social vivido no mundo do sertão. Cada passo de distanciamento da região sertaneja não produzia um afastamento da constituição do ambiente escolar, mais produzia a falta das praticas letradas, as regiões do sertão não possuem funções profissionais que exijam o conhecimento da leitura e escrita, em um pais onde a o direito a educação não e existente, o ingresso de muitos alunos na escola se torna dependente de políticas publicas onde fica ao encargo dos grupos monetários para a elaboração social onde vivem. Alguns dos alunos que se deslocaram do meio sertanejo para São Paulo, regressaram ao seu meio de origem devido a dificuldade que encontravam em sua rotina ao tentarem manter-se na cidade. Esses declaravam os empecilhos de encontrar empregos que trouxessem alternativas de condições de empregados domésticos.

Durante as entrevistas muitos alunos relatavam almejar o retorno para sua origem, outros já anunciavam o desejo de manter-se na região paulistana, dos que declaravam a vontade de regressar não tinham em mente uma previsão para o retorno do tempo que tinham essa hipótese apresentavase com uma data indeterminada e não haviam acontecimentos ou situações que os fizessem tomar tal atitude de forma tão rápida. Outros que relatavam a vontade de permanecer na cidade de São Paulo, já haviam adquirido os hábitos e modo de vida da cidade grande, esses já acostumados ao ritmo mais acelerado, e pelo o fato de ainda conseguir uma renda maior do que a do sertão. Devido a situação de deslocamento, iniciativas de melhores perspectivas, o futuro para esses alunos tornarase imprevisível, envolvidos pelas incertezas, da e grandes diferenças encontradas entre o campo e o trabalho, família, solidão, asfalto, terra, agito e silencio fatores estes que os causavam indecisão. A hesitação na vida desses alunos entre a idéia do retorno e da permanecia tornava-se como um encaixe, dos que desejavam o regresso tinha-se o anuncio do mapeamento rural da volta, os que tinham intenção de permanecer enfatizavam o inverso do que a vida sertaneja podia oferecer.

Rafaela Gomes Pinheiro 